\title{
Chemical composition and quality loss during technological treatment in coho salmon (Oncorhynchus kisutch)
}

\author{
Julia Vinagre ${ }^{1}$, Alicia Rodríguez ${ }^{1}, \mathrm{M}^{\mathrm{a}}$ Angélica Larraín ${ }^{1}$, and \\ Santiago P. Aubourg ${ }^{2, *}$
}

1 Department of Food Science and Chemical Technology. Facultad de Ciencias Químicas y Farmacéuticas. Universidad de Chile, Santiago (Chile).

2 Department of Food Technology. Instituto de Investigaciones Marinas (CSIC), Vigo (Spain)

* Correspondent: +34986231930 (phone),+34986292762 (fax), saubourg@iim.csic.es 


\begin{abstract}
$\underline{\text { ABSTRACT }}$
Coho salmon (Oncorhynchus kisutch) supports an important farming production in parallel with capture delivery, giving rise to products of great economic importance in many countries. This review covers the research carried out during the last decades related to its employment as a food product. In a first part, studies carried out concerning the chemical constituent composition and nutritional value are reviewed; a special attention is accorded to the wild/ farmed fish comparison and to the effect of diet on lipid composition variations. In agreement to the great lability of chemical constituents of aquatic foods, the second part of the manuscript provides a revision of coho salmon research related to the chemical component changes produced during technological processing and their effects on nutritional and sensory losses; in this case, a special attention is accorded to studies employing advanced technological strategies focused to partially inhibit the development of the different damage pathways.
\end{abstract}

Keywords: Oncorhynchus kisutch; wild; farmed; chemical composition; nutritional value; processing; storage; quality loss 


\section{INTRODUCTION}

Coho salmon (Oncorhynchus kisutch), also called silver salmon, is an anadromous fish belonging to the Salmonidae family. This species is closely related to other four ones (sockeye or red salmon, Oncorhynchus nerka; chum or dog salmon, Oncorhynchus keta; pink or humpback salmon, Oncorhynchus gorbusha; chinook or king salmon, Oncorhynchus tshawytscha), all belonging to the same genus and known under the common name of "Pacific salmon".

The traditional range of coho salmon has run from both sides of the North Pacific Ocean, from the Anadyr river and Kamchatka peninsula in Russia south towards Hokkaido (Japan), around the Bering Sea to Point Hope (Alaska, USA) and British Columbia (Canada), and southways to Monterey bay (California, USA) and Mexico. Coho salmon have also been introduced in all Great Lakes, as well as in many other landlocked reservoirs throughout North America. Adult individuals are known to return to the rivers where they were born to mate; they spawn only once and then die. The young fish emerge in springtime and usually live in fresh water for 1-2 years (sometimes up to 4 years); later, they migrate at night to freshwater lakes or to the sea. Upon reaching the sea, the smolts remain close to the coast for a certain time, eating planktonic crustaceans and insects. As they grow, they migrate farther out into the sea and hunt larger organisms such as jellyfish, squids and small fishes. Contrary, they can be hunted by various bigger fishes, birds, mammals and lampreys. The common size of an adult coho salmon may measure round 70 and $60 \mathrm{~cm}$ for male and female, respectively, being the average weight in the range $3-4 \mathrm{~kg}$.

Most fish and other aquatic species give rise to products of great economic importance in many countries, being a basic source of food for all populations of the 
world. The demand for such products has been increasing steadily over the last century and shows no signs of lessening. As a result, fishing has induced serial depletions during the last decades, long masked by improved technology, geographic expansion and exploitation of previously spurned species lower in the food web (Pauly et al., 2002). According to this worldwide decline of ocean fisheries stocks, fish technologists and the fish trade have turned their attention to the aquaculture development as an increasing source of fish and seafood products. In addition to affording a product of consistent quality, farming can provide a constant supply to consumers and control of the various production stages, these including feeding and slaughtering conditions. In addition, fish can be grown economically by using formulated feeds that can optimize cost and/or quality considerations and consumer needs (Paterson, Goodrick \& Frost, 1997).

Related to coho salmon, captures of this species have experienced marked decreases as a result of human-induced and natural factors during the last decades of the last century. As a result, application of aquaculture technology on this species was envisaged and successfully employed. Actually, an important farming production is being obtained in countries such as Chile, Japan, and Canada (FAO, 2007a), in parallel with capture production in countries such as USA, Canada, Russian Federation, and Japan (FAO, 2007b).

Farmed and wild aquatic foods are known to provide high contents of important chemical constituents for the human diet, such as nutritional and digestive proteins including high levels on essential amino acids (lysine, methionine, and so on), lipidsoluble vitamins ( $\mathrm{A}$ and $\mathrm{D}$, namely), microelements (I, F, $\mathrm{Ca}, \mathrm{Cu}, \mathrm{Zn}, \mathrm{Fe}$ and others) and polyunsaturated fatty acids (PUFA), specially those belonging to the $\omega 3$ series (Simopoulos, 1997). However, aquatic species provide highly perishable products 
whose freshness and quality rapidly declines post-mortem. From the moment they are caught or slaughtered till they are ready before attaining the consumer, a more or less extensive chain of processing steps is to be carried out. Thus, chemical composition is known to undergo a wide number of deteriorative pathways such as endogenous enzyme activity, microbiological activity, non-enzymatic lipid oxidation and browning, and enzymatic browning (Aubourg, 2008). The relative incidence of each damage mechanism will depend on the kind of technological process applied and on the concrete chemical composition of the species involved. Consequently, great efforts ought to be carried out in order to guarantee the retention of sensory, nutritional and safety values of raw or starting material.

The present review focuses the coho salmon species and covers the research carried out during the last decades related to its employment as a food product in the human diet. In a first part, research carried out concerning the chemical constituent composition and nutritional value (namely, lipids and proteins) is reviewed; in it, a special attention is accorded to the wild/ farmed fish comparison and to the effect of diet on lipid composition variations (total and lipid classes content; fatty acid composition). In agreement to the great lability of chemical constituents in aquatic foods, the second part of the manuscript provides a revision of studies related to the chemical component changes produced during the technological processing (refrigeration, chilling, freezing and frozen storage, canning and other thermal treatments) and their effects on the nutritional and sensory quality losses; in this case, a special attention is accorded to research employing advanced technological strategies (modified atmosphere packaging, physical pre-treatments, binary systems, antioxidant presence, etc.) focused to partially inhibit the development of the different damage pathways. 


\section{CHEMICAL COMPOSITION STUDIES}

\subsection{Proximate composition}

First studies related to proximate composition of coho salmon correspond to wild fish. Thus, Karrick and Thurston (1964) studied variations in composition from year to year, within the season, from fish to fish, and from different fish sections (nape, centre and tail). Content ( $\mathrm{g} / 100 \mathrm{~g}$ muscle) obtained on chemical constituents was included in the following ranges: 66.9-77.2 (moisture), 20.0-22.8 (protein), 1.6-2.5 (lipids) and 1.1-1.3 (ash). A wide lipid content variation was found, although it could not be correlated with the size of the fish, the catching season, or the catching year. However, the nape contained the highest lipid content and the lowest water and protein contents; meantime, the tail showed to contain the lowest lipid content, but the amount of protein was similar to that of the centre steak section. Fatty deposits were shown to exist in the belly flap, the dark meat along the side, and the dorsal layer along the back of the fish. These tissues had high concentrations of oil even when the entire edible flesh had a low amount of oil. In a further research (Shirai, Fuke, Yamaguchi \& Konosu, 1983a), similar values (g/ 100g muscle) to the above reported were obtained in wild fish concerning moisture (74.1-75.1), protein (21.9-23.0), lipids (1.3-3.4) and ash (1.3) contents.

According to the coho salmon farming development in the eighties of last century, several comparative studies were achieved to assess possible composition differences. Thus, Hata, Sato, Yamaguchi, Ito and Kuno (1988), found a marked difference in lipid content of ordinary muscle between cultured and wild fish; the former showed to contain lipid levels about four times higher than the latter. The chemical compositions of dark muscle corresponding to both kinds of fish, however, 
resembled each other. According to this, Yamaguchi, Sato, Ito, Moritani and Hata (1988) obtained (g/ 100g muscle) a higher moisture content in wild than in farmed fish (61.7 versus 51.7-55.5 range), while the opposite result was obtained when lipid content was evaluated (5.4 versus 17.4-20.2 range), this according to the known inverse ratio between both constituents (Piclet, 1987). Additionally, Higgs, Skura, Dosanjh, Yan, Powrie and Donaldson (1989) found no differences in ash and protein contents between farmed and wild salmon; however, according to previous research, the former had more lipid and less moisture in muscle tissue than the latter.

A comparative study concerning wild and cultivated coho salmon was directed to raw and cooked fish for proximate composition (Nettleton \& Exler, 1992). Raw values provided the same conclusions as in previous research. After the cooking process, differences in proximate composition (namely, moisture and lipid contents) were retained between wild and farmed fish, being all nutrient values higher in cooked samples than in their corresponding raw ones due to moisture loss during cooking.

Recent research accounts for proximate composition in farmed fish. Varying values are obtained, specially concerning lipid and water values, according to the great influence exerted by the diet composition. Thus, Perea, Gómez, Mayorga and Triana (2008) showed a relatively fatty fish (60.0-68.6, 19.4-20.9, 7.4-17.0, and 1.1-1.3, for moisture, protein, lipids and ash, respectively; g/ 100g muscle), while Ortea, Rodríguez, Tabilo-Munizaga, Pérez-Won and Aubourg (2010) presented a leaner fish (72.4 \pm 1.0 , $20.3 \pm 0.4,4.7 \pm 1.3$, and $1.0 \pm 0.1$, for moisture, protein, lipids and ash, respectively; g/ $100 \mathrm{~g}$ muscle). 


\subsection{Protein-like component analysis}

Different studies have been carried out related to protein-type compounds in coho salmon. Such research has been focused on protein analysis, amino acid and peptide composition and enzyme presence and activity.

\section{$\underline{\text { 2.2.1. Proteins }}$}

Egg proteins of coho salmon were studied by Markert and Vanstone (1971). As a result of a chromatographic analysis (sephadex G-200), three major proteins were found in the soluble fraction (lipovitellin, phosvitin and a third serum protein named “ $\beta$ '-component"), being their molecular weight values of 390, 27 and $30 \mathrm{kDa}$, respectively. Immunological techniques showed that these proteins were also found in the plasma of sexually maturing females but not of sexually maturing males and were absent from spawning females. Thus, it was suggested that production of yolk proteins ceases as eggs become fully developed. In this research, support was also obtained for classifying the $\beta$ '-component not as a livetin protein but as an egg protein, like lipovitellin and phosvitin.

Identification of fish species has been gaining an increasing importance in the seafood industry because of the labelling regulations imposed by many countries all over the world. With this objective in mind, the sarcoplasmic protein fraction was comparatively studied in different related species (Coduri, Bonatti \& Simpson, 1979). By employment of vertical plate gel electrophoresis, rainbow (Oncorhynchus mykiss), brook (Salvelinus fontinalis), and brown (Salmo trutta) trout were easily distinguished from coho (O. kisutch), chinook (O. tschawytscha), and sockeye (O. nerka) salmon. No correlation or relationship appeared to exist between pigment concentration and 
electrophoresis protein pattern, so that differences could be observed regardless of the level of pigmentation.

\subsubsection{Amino acids and peptides}

The composition of free amino acids and related compounds in the dorsal muscle extract ( $80 \%$ aqueous ethanol) of coho salmon was studied (Shirai, Fuke, Yamaguchi \& Konoso, 1983b). A high content of dipeptide anserine (521-574 mg/ 100g muscle) and fairly low levels of histidine, taurine, alanine and glycine could be observed. Total extractive non-protein $\mathrm{N}$ was included in the range $363-365(\mathrm{mg} / 100 \mathrm{~g}$ muscle), being the percentage to total nitrogen of muscle in the range 9.9-10.3.

The amino acid composition of several tissues of cultured and wild coho salmon were measured and compared (Hata et al., 1988). The major amino acids of the flesh were aspartate, glutamate, leucine and lysine, with no marked difference in amino acid composition between the cultured and wild fish. Extractive-nitrogen and free amino acid contents were higher in the liver and viscera than in other tissues. Free amino acids abundantly found in ordinary muscle, liver and testis were histidine, glutamine, and argenine, respectively; meantime, the dark muscle showed to contain high levels of free taurine, while the ordinary muscle had large amounts of anserine.

Glutathione (GSH) presence in fish has attracted a great attention according to its role in oxidation inhibition and to its possible effect on flavour and taste. Thus, contents in GSH and glutathione disulphide (GSSG) were studied by high performance liquid chromatography (HPLC) in different kinds of marine species (Ueda, Hibino, Kohmura, Kuroda, Watanabe \& Sakaguchi, 1998). Values reported for both molecules in coho salmon muscle (9.22 and $0.38 \mathrm{mg} / 100 \mathrm{~g}$ muscle, respectively) were found among the highest ones of the different species tested. A comparative study of the 
flavour contribution of both GSH and GSSG was achieved; it was concluded that GSSG did not contribute to flavour as much as GSH.

\subsubsection{Enzyme presence and activity}

Many studies have implicated lysosomal enzymes in the post-mortem changes of fish muscle tissue (namely, softening), although lysosomal enzyme activity in muscle tissue is known to be lower when compared to activity in liver and lung macrophages. Once living processes have ceased in the fish body, transport of lysosomal enzymes from ruptured lysosomes would proceed via diffusion, but early activity would be limited to that occurring at the original site of the lysosomes. In order to localize the lysosomes within the muscle tissue of coho salmon, a light and electron microscopy study was achieved (Steiner, Broderson \& Liston, 1984). As a result, three distinct populations of lysosomes were identified on the basis of their location within the tissue: i) in connective tissue cells associated with the connective tissue compartment, ii) within but at the periphery of the muscle cells, and iii) within the muscle cells distributed among the myofibrils.

Activity of proteinase extracts from coho salmon viscera was examined on three different substrates (azocasein, haemoglobin and casein) (Heu \& Ahn, 1999). Extracts were subjected to fractionation using acetone $(0-55 \%$ in water) or ammonium sulphate (30-70\% in water). Individual proteinases detected in fractions were cathepsin D- and pepsin-like enzymes at pH 3.0, cathepsin L-, B-, H- and G-like enzymes at pH 6.0 and trypsin- and chymotrypsin-like enzymes at $\mathrm{pH}$ 8.0. Activity of fractionated viscera proteinases were compared with those of several commercial proteinases; such commercial proteinases showed higher activity on azocasein than the salmon viscera proteinases but lower amidolytic activity at $\mathrm{pH} 6.0$ and 8.0 towards synthetic substrates. 
As a result, a commercial potential interest of fractionated proteinases from coho salmon viscera was suggested.

\subsection{Lipid component analysis}

\subsubsection{Fatty acid composition}

Steak samples taken ahead of the dorsal fin were used for the fatty acid analysis in wild (Pacific coast of the USA) coho salmon (Gruger, Nelson \& Stansby, 1964). Most abundant fatty acids found were (g/ 100g total fatty acids): C 18:1 (18.6), C 22:6 (13.8), C 20:5 (12.0), C 16:0 (10.2) and C 20:1 (8.4); the $\omega$ series corresponding to each unsaturated fatty acid was not elucidated. Some different distribution was found when studying entire and homogenised wild fish captured in the Yaquina river near Nashville (Oregon, USA) (Saddler, Lowry, Krueger \& Tinsley, 1966); in this case, the major fatty acids were (g/ 100g total fatty acids): C 18:1 $\omega 9$ (19.3), C 16:0 (14.7), C 18:2 $\omega 6$ (11.7), C 16:1 $\omega 7$ (9.0), C 22:6 $\omega 3$ (7.4), C 18:0 (6.1) and C 18:4 $\omega 3$ (4.3).

Coho salmon from the Pacific coast is known to have been introduced in the Lake Michigan, so that the entire life of the fish would be completed in the fresh water of this lake. In 1969, Braddock and Dugan studied the fatty acid composition of lipids from steaks ahead the dorsal fin of late September spawning coho salmon corresponding to the mentioned lake. An unusual high level (g/ 100g total fatty acids) of C 18:1 $\omega 9$ (29.3) was obtained, followed by C 16:1 $\omega 7$ (10.9), C 16:0 (10.8), C 22:6 13 (5.2), C 18:2 $\omega 6$ (5.0), C 22:5 $\omega 3$ (4.2) and C 20:5 $\omega 3$ (3.2) fatty acid contents. In a further study on wild coho salmon (Hardy \& King, 1989), the fatty acid profile was studied in fish caught during the migration from ocean feeding areas to the natal rivers of origin; as in the previously mentioned study, a high (g/ 100g total fatty acids) C 18:1 
$\omega 9$ proportion was obtained (24.4\%), that was followed by contents on C 16:0 (12.7), C $22: 6 \omega 3$ (9.9), and C 20:5 $\omega 3$ (6.7) fatty acids.

Fatty acid studies have proved that freshwater fish contains considerably more $\mathrm{C}$ 18:2 $\omega 6$, markedly less C 20:5 $\omega 3$ and somewhat less C 22:6 $\omega 3$ than do saltwater fish (Stansby, 1967). The ocean-caught, mature coho salmon has shown to resemble the salt water species in fatty acid content; on the other hand, the fatty acid composition of the immature, river-caught coho salmon proved to resemble more closely that of the freshwater species. It appeared that the typical fatty acid pattern of marine fish, which involves low contents on C 18:2 $\omega 6$ and unusually high $C$ 22:6 $\omega 3$ and C 20:5 $\omega 3$ contents, is less apparent for the freshwater forms of ocean fish. Fingerlings of anadromous species such as coho salmon showed to deviate even more from this pattern (Stansby, 1967).

When coho salmon migrate to their spawning ground, a series of critical metabolic changes are known to take place which terminate in death after spawning. During this period the salmon do not feed but utilise fat stored in tissues for energy and for final development in roe. Salmon at the time of spawning are of very poor quality. These inferior or "spent" salmon are commercially differentiated from normal high quality product. Thus, an investigation was initiated to find a chemical means, based on differences in fatty acid profile analysis to distinguish between normal and spent salmon (Iverson, 1972). As a result, some conclusions were obtained concerning the employment of long chain monounsaturated fatty acids (MUFA) by the migrating salmon. However, differentiation between prime and spent salmon by a fatty acid compositional approach would not be likely to be achieved as a result of larger internal (namely, genetic, anatomical and physiological factors) and external (namely, feed availability and water temperature factors) variations. 
Several studies have focused on the comparative fatty acid composition of wild and farmed fish, most of them with reference to the PUFA content, $\omega 3$ content and $\omega 3$ / $\omega 6$ ratio value. Thus, Yamaguchi et al. (1988) found that the main fatty acids (g/ $100 \mathrm{~g}$ total fatty acids) of edible wild fish were C 22:6 (18.6), followed by C 20:1 (16.0), C 16:0 (14.9), C 18:1 (13.3), C 22:1 (9.1) and C 20:5 (7.6) ( $\omega$ series were not elucidated in this study); a different pattern for cultivated fish was found in the sense that $\mathrm{C}$ 18:1 was the major one (21.6\%), followed by C 16:0 (14.9-16.5), C 22:6 (12.9-14.4) and C 20:5 (10.0-11.4). In this sense, Higgs et al. (1989) reported that muscle lipids of wild salmon had higher content of C 20:5 $\omega 3$ and C 22:6 $\omega 3$ and lower content of $\omega 6$ fatty acids than farmed salmon; this difference would be, however, offset by the higher lipid content of farmed salmon compared to the wild one. Contrary, Roch, Tesar and Paterson (1988) found similar or greater total $\omega 3$ contents in farmed coho salmon than in wild one.

According to the great importance accorded to coho salmon as a farmed product, its fatty acid composition has widely been studied. Thus, Ota, Sasaki, Abe and Takagi (1990) found that the most abundant fatty acids (g/ 100g total fatty acids) were C 16:0 (17.6) and C 18:1 $\omega 9$ (8.1), followed by two $\omega 3$-PUFA (C 22:6 $\omega 3$ and C 20:5 $\omega 3,12.5$ and 8.1 , respectively); a 6.91 value was obtained for the $\omega 3 / \omega 6$ ratio. In a recent research, C 18:1 $\omega 9$ (1600-2900 mg/ 100g salmon fillet), followed by C 16:0 (14003100), C 22:6 $\omega 3$ (720-1250), C 18:2 $\omega 6$ (700-2200) and C 20:5 $\omega 3$ (400-1000) were found as the major fatty acids (Perea et al., 2008). Similarly, coho salmon farmed in the South of Chile showed C 18:1 $\omega 9$ and C 16:0 fatty acids as the most abundant ones (19.3 and 20.7, respectively; g/ 100g total fatty acids), followed by C 22:6 $\omega 3$, C 16:1 $\omega 7$ and C 20:5 $\omega 3$ (14.8, 7.7. and 7.1, respectively) (Aubourg, et al., 2005). 


\subsubsection{Diet effect on fatty acid composition}

A great effect of diet on fatty acid composition in farmed fish has been accorded. Consequently, most research has been carried out with the basic objective of reaching a highly nutritional product, which resembles the most possible to the wild one. Thus, Tinsley, Saddler, Krueger and Lowry (1971) studied the effect of diets containing high levels of $\mathrm{C} 18: 2 \omega 6$ on the fatty acid composition of coho salmon; the influence of such fatty acid on transformations in the C 18:3 $\omega 3$ series of PUFA was demonstrated. The same authors (Tinsley, Krueger \& Saddler, 1973) developed a stepwise multiple regression equations procedure to express the fatty acid content of fingerling coho salmon as a function of fish length and the time the salmon had been maintained on a specific diet. As a result, high correlation coefficients from the multiple regressions were obtained for most of the fatty acids studied, so that the fatty acid content of individual fish could be predicted with a fair degree of precision from the derived equations. Under the specified experimental conditions, changes in wet weight, the total mass of fatty acids per salmon, and the mass of most individual fatty acids per salmon showed to be dependent on the time and on the interaction of diet time with salmon length.

In a further research, the growth response of coho salmon to different isocaloric diets containing varying levels of $\omega 3$ and $\omega 6$ fatty acids was investigated $(\mathrm{Yu} \&$ Sinnhuber, 1979). The fish conversion efficiency and the effect on fatty acid composition of the fish phospholipids (PL) was determined. The optimum level of dietary $\omega 3$ fatty acid showed to range from 1.0 to 2.5 (g/ $100 \mathrm{~g}$ total fatty acids). It could be observed that dietary $\omega 6$ fatty acid content higher than $1 \%$ depressed the fish growth. Additionally, only the incorporation of $\omega 6$ fatty acids into PL was inhibited by the increasing levels of dietary C 18:3 $\omega 3$ fatty acid. The same authors (Yu \& 
Sinnhuber, 1981) checked beef tallow as a source of dietary energy for coho salmon fish when used in conjunction with a fish oil. It was observed that the final fish weight was greatest with a diet containing $8 \%$ each of tallow and salmon oil. Fatty acid analysis indicated that the dietary salmon oil provided adequate quantities of the $\omega 3$ fatty acids required by the coho salmon. Fish body lipid saturation showed to increase only slightly as the concentration of tallow in the diet increased. It was concluded that beef tallow would provide a good source of dietary energy when used in conjunction with a fish oil rich in $\omega 3$ fatty acids.

Canola oil, pork lard and herring oil singly and in combination were assessed as supplemental sources of dietary lipid for juvenile coho salmon (Dosanjh, Higgs, Plotnikoff, McBride, Markert \& Buckley, 1984). It was concluded that canola oil, pork lard and a blend of these lipid sources could be excellent alternative types of supplemental dietary lipid for coho salmon under these test conditions. Such fat materials are known to provide the advantages of being more available, often less expensive, and less prone to oxidation than marine oil.

The effect of replacing synthetic antioxidants by natural ones in the diet provided to growing coho salmon was studied (Ortiz, Larraín, Vivanco \& Aubourg, 2009). For it, a commercial diet including synthetic antioxidants (butylated hydroxytoluene-ethoxyquin mixture) was provided to coho salmon in parallel with two diets including natural antioxidants (tocopherol isomers-rich mixture; tocopherol isomers-rosemary extract mixture). Once individual salmons attained ca. $2500 \mathrm{~g}$ weight, fish were withdrawn, sacrificed and analysed. No effect could be assessed on the fatty acid composition of the salmon muscle, this including the polyene index, among the

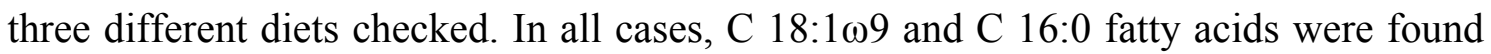
the most abundant fatty acids, followed by C 22:6 $\omega 3, \mathrm{C} 16: 1 \omega 7$ and $\mathrm{C} 20: 5 \omega 3$. 


\subsubsection{Carotenoid content and tissue colour}

Salmon cannot synthesize or biologically transform carotenoid precursors into the specific astaxanthin (AX) carotenoids found in their tissues. Despite its obvious presence, colour is not an intrinsic component of the flesh, but results from the deposition of dietary carotenoids. Fish coloration in salmon is recognised as an important attribute which influences product marketability and consumer acceptance. For wild fish, marine zooplankton and nekton, natural foods of salmonids, provide salmon with their main source of these pigments. Related to farmed fish, most research has been carried out in order to get a salmon product including the wild red-orange colour in farmed salmonid fish.

Concerning coho salmon farming, soy oil-extracted carotenoids from red crab (Pleuroncodes planiceps) were included in the diet (Spinelli \& Mahnken, 1978); it could be observed that the amount of carotenoid deposited in the flesh of the fish was related to the carotenoid content of the diet and to the weight of the fish; additionally, no correlation between carotenoid and fat contents was found. In a further experiment (Mori et al., 1990), cultured coho salmon diet was supplemented with either Antartic krill, or with littoral mysid shrimps, both well known as being rich in red carotenoid AX content; pigmentation of the flesh of cultured coho salmon was examined, so that

salmon flesh showed to accumulate carotenoid approximately equal to those observed in wild salmon (0.6-1.0 mg/100 g muscle) within 127 days. Such values agreed to those obtained for raw farmed fish during a chilled storage experiment $(0.9 \pm 1.5$; Aubourg et al., 2005). Yamazaki, Ito, Nozaki, Narita and Hirota (1983) studied the carotenoid deposition in different parts of the edible muscle of coho salmon by providing a diet supplemented with krill (Euphausia superba Dana); no significant differences in AX content between fish regions could be concluded, although some different mean values 
were obtained $(0.35 \pm 0.04,0.30 \pm 0.05$ and $0.28 \pm 0.05 \mathrm{mg} / 100 \mathrm{~g}$ muscle for back, belly and tail, respectively).

Coho salmon was examined for distribution and nature of carotenoids in muscle (Henmi, Iwata, Hata \& Hata, 1987). AX and canthaxanthin (CX) were found as the major carotenoids present, being proved that both were bound to muscle actomyosin by weak hydrophobic bonds. In a further research (Henmi, Hata \& Hata, 1989), the way carotenoids combine with salmon actomyosin and the nature of the astaxanthin and/or CX complex was studied. It was proposed that $\mathrm{AX}$ and/or $\mathrm{CX}$ in coho salon muscle binds with one beta-ionone ring to a hydrophobic binding site which exists on the surface of actomyosin. The binding of carotenoids to actomyosin would not be specific, so that actomyosin could associate with many kinds of carotenoids and lipids. Finally, model systems consisting on combination of actomyosin from white and dark coho salmon muscle with AX or CX were analysed (Henmi, Hata \& Hata, 1990). It could be observed that actomyosin bound with a high affinity to AX. A correlation between surface hydrophobicity of actomyosin and combination of $\mathrm{AX}$ and/or CX with actomyosin was observed.

\subsubsection{Other lipid components}

A comparative study of lipid group and classes from wild and farmed coho salmon was achieved (Yamaguchi et al., 1988). Triglyceride (TG) was found to be the most abundant component of lipids in all kinds of tissues investigated. When compared to farmed fish, wild fish white muscle showed a lower TG content, but higher for the remaining lipid group and classes analysed (polar lipids; free sterols; monoglycerides; diglycerides; free fatty acids, FFA). For both kinds of fish, the dark muscle showed a higher TG content and a lower polar lipid content than in the white muscle. In a further 
research (Ota et al., 1990), lipid composition was analysed in farmed coho salmon. Thus, TG were found as the most abundant lipid class ( $89.9 \mathrm{~g} / 100 \mathrm{~g}$ lipids), followed by total PL (5.6) and free sterols (2.3); hydrocarbons and sterol esters were also detected.

Wild and cultivated coho salmon was analysed for cholesterol presence (Nettleton \& Exler, 1992). Cholesterol content was found to be independent of fat content, supporting similar values in wild and cultivated samples $(47-52 \mathrm{mg} / 100 \mathrm{~g}$ muscle). Tocopherol isomer presence was studied in farmed coho salmon white muscle (Rodríguez, Losada, Larraín, Quitral, Vinagre \& Aubourg, 2007); levels found for $\alpha$ and $\gamma$ isomers were $11.1 \pm 0.5$ and $3.3 \pm 0.4 \mathrm{mg} / \mathrm{kg}$ fish muscle, respectively. In a further research (Aubourg, Tabilo-Munizaga, Reyes, Rodríguez \& Pérez-Won, 2010), the same authors found lower levels for both isomers (5.6 \pm 0.8 and $2.6 \pm 0.2$, respectively); such differences were attributed to the fact that farmed fish individuals in both experiments were obtained from two different aquaculture facilities.

\subsection{Other chemical component analysis}

Adenosine triphosphate (ATP) degradation is considered an important damage pathway closely related to freshness loss in fish. In this sense, an enzymatic study concerning the ATP degradation in wild coho salmon fillets was achieved (Stone, 1970). It was proved that crude extracts of coho salmon fillets contained both adenosine aminohydrolase and 5'-adenosine monophosphate-aminohydrolase, while adenine aminohydrolase activity was not detected. Such results suggested that the enzymatic deamination of 5'-adenosine monophosphate would contribute to the 5'-inosine monophosphate (IMP) formation during the post-mortem changes of this salmon species. 
The transition of prime ocean-dwelling coho salmon into spawning condition fish occurs as approaches brackish waters and rivers, and this maturation involves a cessation of feeding and a mobilisation of muscle lipids and carotenoid pigments into the gonads and skin. An investigation was envisaged to quantitatively measure the characterising volatile aroma compounds during maturation of coho salmon (Josephson, Linsya \& Stuiber, 1991a). For it, volatile aroma compounds from freshly harvested prime and spawning-condition salmon were quantitatively measured. Regardless of stage of maturity, both kinds of salmon provided 1-octen-3-one, 1,5-octadien-3-one, 1octen-3-ol, 1,5-octadien-3-ol, 2-octen-1-ol, and 2,5-octadien-1-ol which contributed distinct and characteristic plant-like aromas to the fish. More pronounced aromas of spawning-condition salmon were attributed to greater concentration of the 8-carbon compounds in combination with occurrence of (E)-2-nonenal, (E)-2,(Z)-6-nonadienal, 6-nonen-1-ol, and 3,6-nonadien-1-ol which added sweet-, cucumber- or melon-like aroma notes. It was postulated that the 9-carbon compounds may have resulted from biochemical regulation of physiologically active lipid-derived substances which activate mucus secretion in salmon approaching sexual maturity.

Wild and cultivated coho salmon was analysed for aqueous and non-aqueous vitamin contents (Nettleton \& Exler, 1992). For both kinds of fish, vitamin $\mathrm{B}_{12}$ in $100 \mathrm{~g}$ fish muscle met or exceeded the recommended dietary allowance for adults of $2 \mu \mathrm{g} /$ day. Other vitamins showed to provide profitable contents such as niacin (7.34 and 6.65 $\mathrm{mg} / 100 \mathrm{~g}$ muscle for wild and farmed fish, respectively), vitamin A (24-39 and 55-57 retinol equivalents/ $100 \mathrm{~g}$ muscle for wild and farmed fish, respectively), thiamine (0.08$0.10 \mathrm{mg} / 100 \mathrm{~g}$ muscle for both kinds of fish) and riboflavin $(0.12-0.14 \mathrm{mg} / 100 \mathrm{~g}$ muscle for both kinds of fish). However, negligible levels were found for ascorbic acid (0.8-1.4 $\mathrm{mg} / 100 \mathrm{~g}$ muscle) and folic acid (0.01-0.02 mg/ $100 \mathrm{~g}$ muscle) in both wild and farmed 
fish. In a further nutritional study (Perea et al., 2008), contents on P, Ca and Fe were analysed in farmed coho salmon fillets; values obtained were included in the following ranges, respectively: 283-361, 10-24, 2-6 mg/ 100 g muscle.

Volatile compound formation as a result of bacterial species presence in different fish muscles was studied (Nakai et al., 1999). For it, coho (O. kisutch), Atlantic (Salmo salar), chinook (O. tshawytscha) and sockeye (O. nerka) salmon and five commercial samples of hamburger patties were analysed by processing gas liquid chromatography (GLC) data of volatile compounds using the principal component similarity (PCS) technique. PCS scattergrams of samples inoculated with Escherichia coli and Staphylococcus aureus followed by incubation showed the pattern-shift lines moving away from the data point for uninoculated, unincubated reference samples in different directions with increasing incubation time. When the PCS scattergrams were drawn for samples incubated overnight, samples inoculated with the two bacterial species and the uninoculated samples appeared as three separated groups. It was stated that this GLC/PCS approach would have the potential to ensure quality of samples by discriminating good samples from potentially spoiled samples.

Identification and differentiation of ten salmon species (coho salmon included) using deoxyribonucleic acid (DNA)-based methodology was investigated (Russell et al., 2000). Amplification of DNA was carried out using a primer set which amplified a region of the mitochondrial cytochrome $b$ gene. Sequences of polymerase chain reaction (PCR)-amplified DNA from the salmon species were used to select six restriction enzymes allowing species to be uniquely classified. Restriction fragment length polymorphism (RFLP) patterns generated following analysis with each enzyme were resolved using polyacrylamide gel electrophoresis (PAGE) and visualised by silver staining. Results indicated that it was possible to differentiate between all ten salmon 
species and the technique would provide a simple and low cost-effective method for identifying salmon species present in processed salmon products.

A PCR-based method for identification of genetically modified coho salmon was developed, so that it could serve as basis for an official method to identify transgenic coho salmon (Rehbein, Devlin \& Rüggeberg, 2002). The coho salmon contained an "all-salmon" gene-construct (OnMTGH1) consisting of the metallothionein-B-promoter fused to the full-length type-1 growth hormone gene, both from sockeye salmon $(O$. nerka). For it, two PCR were performed. The first served as a control for amplifiable DNA present in the sample, and at the same time as a tool for species identification by PCR-RFLP test. For this PCR, universal primers located in the mitochondrial cytochrome $\mathrm{b}$ gene were used. The second PCR, working with primers located within the construct, was able to detect the genetic alteration. According to the results obtained within a fifteen collaborative laboratories, in each case the species and genetic modifications were assigned correctly.

\section{CHEMICAL CHANGES AND QUALITY LOSS DURING COHO SALMON}

\section{PROCESSING}

\section{$\underline{\text { 3.1. Fresh and refrigerated products }}$}

A quality study was conducted to evaluate sensory, chemical, and microbiological changes occurring in wild coho salmon stored in refrigerated conditions $\left(4.5^{\circ} \mathrm{C}\right)$ under modified atmospheres (Brown, Albright, Watts, Heyer, Spruce \& Price, 1980). For it, salmon steaks were held in atmosphere containing $20 \%$ or $40 \% \mathrm{CO}_{2}$ (balance air), with or without $1 \% \mathrm{CO}$, being compared to air-control atmosphere. After 
7 days of storage, air control samples provided a slime appearance, that was absent on samples corresponding to gas treatments. Samples held in air were judged by panellists to have stronger aromas than others held under $\mathrm{CO}_{2}$ at either level. Values for thiobarbituric acid (TBA) value (lipid oxidation development) were low in all cases; hypoxanthine (Hx) values (autolysis development) varied widely, with no particular effect due to modified atmosphere. However, storage under $\mathrm{CO}_{2}$ was found effective in reducing the formation of trimethylamine (TMA) and ammonia (microbial activity). It was concluded that modified atmospheres greatly inhibited microbial growth and were effective in preventing undesirable sensory changes at the levels $\left(20 \%\right.$ and $\left.40 \% \mathrm{CO}_{2}\right)$ employed.

In a further study, whole wild coho salmon was kept in ice up to 14 days (Barnett, Nelson \& Poyski, 1991). Sensory analyses showed that when stored under ice, coho salmon remained at the premium grade for about 7 days; this was followed by a short period of average sensory quality, becoming borderline after 13 days. Bacterial growth remained low during the first 8 to 9 days of storage, being this stage followed by a rapid growth phase. Chemical indicators used in this study to determine freshness and quality losses in the iced salmon indicated that IMP in premium grade ranged between 2.5 and $4.0 \mu$ moles/g muscle, while the concentration of Hx was less than $1.0 \mu$ moles/ $\mathrm{g}$ muscle; at the end of the iced storage, coho salmon muscle provided an IMP content of about $1.9 \mu$ moles/g muscle and a Hx content of $1.8 \mu$ moles/g muscle. The maximum concentration of TMA in top quality coho salmon was about $1.0 \mathrm{mg}$ TMA-N/ $100 \mathrm{~g}$ muscle, being ranged between 3.5 and $4.5 \mathrm{mg}$ in the poorest quality salmon. For lipid oxidation development, premium quality iced coho salmon were characterized by a TBA number of $2 \mu$ moles/ $100 \mathrm{~g}$ or less, being this value quite constant throughout the whole experiment. 
Wild coho salmon freshness was assessed according to ATP nucleotide degradation by means of capillary electrophoresis and an immobilized enzyme procedure during storage on ice $\left(0-4{ }^{\circ} \mathrm{C}\right)$ and at $20^{\circ} \mathrm{C}$ (Luong, Male, Masson \& Nguyen, 1992). Degradation of IMP, inosine and Hx were determined, so that both $\mathrm{K}$ and $\mathrm{H}$ values were determined. The two analytical procedures agreed in the sense that $\mathrm{K}$ and $\mathrm{H}$ values increased with storage time and temperature. A fast $\mathrm{K}$ value increase was observed in fish kept on ice, this reaching $90-100 \%$ range values at day 3 ; in the case of $\mathrm{H}$ values, scores included in the $90-100 \%$ range were only obtained at day 13 . $\mathrm{H}$ value analysis was presented as a promising tool for freshness assessment as being directly related to the Hx concentration.

It is well known that MUFA are less prone to oxidation than PUFA. Thus, increasing the MUFA content of fish flesh through dietary manipulation might improve storage stability and sensory characteristics of the corresponding product. According to this, a feeding study was achieved to determine if substituting sunflower oil (highly containing oleic acid) for herring oil in formulated salmonid diets affected sensory attributes of fillets from farmed coho salmon (Skonberg, Rasco \& Dong, 1993). Two feeding trials were conducted in which coho salmon were fed diets containing either sunflower oil or herring oil as the supplemental lipid source $(12.4 \%$ of the diet by weight) for 6-8 weeks. Then, salmon fish was slaughtered and kept as fillet at $5^{\circ} \mathrm{C}$ up to 10 days. At that moment, sensory panellists were able to differentiate between fillets from the two dietary treatments based on aroma, and determined that the fillets corresponding to the herring oil diet had a "fishier" aroma than their corresponding fillets from sunflower oil diet. Results suggested that increasing the MUFA level in fish by feeding a high MUFA finishing diet could potentially decrease oxidative rancidity of 
the corresponding fish product, and thereby improve the shelf life and sensory characteristics of the product.

In a parallel study to the above mentioned (Skonberg et al., 1993), fatty acid profiles were analysed in refrigerated $\left(5^{\circ} \mathrm{C}\right.$ up to 8 days) farmed coho salmon muscle after feeding with diets containing either supplemental herring oil or high oleic acid sunflower oil (Skonberg, Rasco \& Dong, 1994). The effects of fatty acid composition on shelf life of fresh fillets were quantified by the TBA assay and compared to sensory acceptance. It could be observed that muscle from fish fed with sunflower oil diet had twice the concentration of oleic acid (approximately $25 \mathrm{~g} / 100 \mathrm{~g}$ lipid) than muscle from fish fed with the herring oil diet (approximately $12 \mathrm{~g} / 100 \mathrm{~g}$ lipid). Maximum concentration of oleic acid in the muscle was obtained after only 2 weeks of providing the sunflower oil diet. Data indicated that accumulation of oleic acid in coho salmon muscle was rapidly achieved when a high oleic acid diet was fed. Differences between the fish receiving the two dietary treatments in fatty acid composition and in concentration of TBA reactive substances in muscle stored at refrigerated temperature were consistent with previously reported differences in aroma perceived by a sensory panel (Skonberg et al., 1993).

Lipid damage produced during chilled storage of farmed coho salmon was studied over a 24-day storage (Aubourg et al., 2005). Lipid hydrolysis (FFA) and oxidation (conjugated dienes; peroxide value; TBA value; fluorescence ratio, FR; browning development) were determined and compared to changes in lipid composition (polyene index; AX) and sensory properties (rancid odour development). Most lipid damage indices developed slowly during storage. Aroma assessment showed a significant rancidity development at day 10 , when compared to the starting fish material; then, non-acceptable values were obtained at day 19. The polyene index 
analysis showed few differences during the storage time, with the lowest mean value at day 19. AX analysis indicated a relatively high content in the white flesh, which was maintained until the end of the experiment. It was concluded that there was a low oxidation development of coho salmon lipids when compared to other fatty fish species under the same chilling conditions. Further, AX contributed to the oxidation stability of coho salmon lipids, due to its free radical scavenger properties.

In a parallel study to the above mentioned (Aubourg et al., 2005), two deteriorative pathways (autolysis and microbiological activity) were studied in farmed coho salmon for 24 days during chilled storage (Aubourg et al., 2007). These changes were assessed by nucleotide degradation (determination of ATP and its degradation compounds) and biochemical ( $\mathrm{pH}$; content of total volatile base-nitrogen; TMA-N; histamine) and microbial (total aerobic mesophiles, TAM; coliforms) indices related to bacterial activity. As a result, an important nucleotide degradation could be assessed according to the fast IMP formation, followed by degradation into inosine and Hx; the $\mathrm{K}$ value was found to be an accurate tool for the measurement of quality loss throughout the whole experiment. Regarding bacterial activity, TAM counts and contents on TMA$\mathrm{N}$ and histamine showed sharp increases after the end of the microbial lag phase (12-17 days); however, values obtained for histamine content and TAM growth showed to remain below acceptable security limits throughout the whole experiment.

The effect of a previous hydrostatic high pressure (HHP) treatment on chilled farmed coho salmon was analysed (Aubourg et al., 2010). In it, three different HHP conditions were applied (135 MPa-30 s; $170 \mathrm{MPa}-30 \mathrm{~s} ; 200 \mathrm{MPa}-30 \mathrm{~s}$; treatments T-1, T-2 and T-3, respectively) and compared to untreated (control) fish throughout a 20 day-chilled storage. Microbial activity and lipid oxidation development were analysed. Assessment of aerobe, psychrotroph, Shewanella spp. and Pseudomonas spp. counts 
and TMA formation showed a marked inhibitory effect of HHP treatment on microbial activity, this effect increasing with the pressure value employed. Related to lipid oxidation development, higher peroxide mean values (10-20 days period) were found in control samples and fish treated under $\mathrm{T}-1$ condition when compared to their counterparts corresponding to T-2 and T-3 treatments; contrary, assessment of TBA value and FR showed higher levels in fish samples corresponding to T-2 and T-3 treatments. In spite of the lipid oxidation development found, polyene index and tocopherol isomer ( $\alpha$ and $\gamma$ ) content did not provide differences as a result of previous HHP treatment.

In a parallel experiment to the above mentioned (Aubourg et al., 2010), the effects of the same HHP conditions on hydrolysis, breakdown and aggregation in chemical constituents of chilled farmed coho salmon were studied (Ortea et al., 2010). As a result, nucleotide degradation was important during the chilled storage in all kinds of samples; however, the $\mathrm{K}$ value did not afford differences related to previous pressure applied. Increased FFA mean values (day 0 values) could be observed in HHP-treated samples when compared to control ones (Figure 1); on the contrary, an inhibitory effect on FFA formation could be observed at the end of the storage (15-20 days) in T-3treated fish as a result of microbial activity inhibition. Meantime, a marked decrease in sarcoplasmic protein content was evident in samples corresponding to T-2 and T-3 treatments. The sodium dodecyl sulphate (SDS)-PAGE analysis of such protein fraction showed a partial loss of a band corresponding to $29 \mathrm{kDa}$; this band was excised, digested with trypsin, analysed by tandem mass spectrometry and identified as phosphoglycerate mutase. 


\subsection{Frozen products}

The effect of previous treatment and different packaging conditions was studied on the quality retention of frozen (up to 14 months at $-18{ }^{\circ} \mathrm{C}$ ) coho salmon steaks ( $\mathrm{Yu}$, Landers \& Sinnhuber, 1969). The use of butylated hydroxyanisole, butylated hydroxytoluene and polyphosphate solutions, starch coating and vacuum packaging to preserve the quality of the frozen steaks was investigated by means of chemical (peroxide value and TBA value) and sensory (flavour, texture and colour) quality indices. It was concluded that frozen coho salmon could retain its quality through the use of antioxidants and appropriate packaging for as long as 14 months. The starch coating technique combined with the use of antioxidant was an effective method of protecting the fish from desiccation and lipid oxidation development. However, vacuum sealing of the fish samples in a can with added antioxidants showed to be the best means of preserving the quality of the frozen salmon.

IMP is a metabolite produced during the ATP degradation that has shown an important role as flavour contributor in fish muscle. In order to assess its content and possible effect on sensory acceptance, a comparative study between fresh and frozenthawed wild coho salmon was achieved (Kemp \& Spinelli, 1969). When frozen and then thawed within 48 hours, coho salmon did not show changes in the rate of IMP degradation compared to fresh samples. It was concluded that the flavour-contributing effect of IMP in thawed fish therefore should be the same as in fresh fish, provided the fish was frozen and stored at or near a temperature of $-29^{\circ} \mathrm{C}$.

The formation of volatile amines during the frozen storage of wild coho salmon was analysed (Gruger, 1972). For it, coho salmon were troll-caught, iced on-board, dressed, glazed and stored at $-28^{\circ} \mathrm{C}$. Sampling was carried out after 37 and 45 months. 
Data provided evidence for the presence of TMA, dimethylamine (DMA) and monomethylamine (MMA) in salmon muscle. Thus, values obtained ranged as follows: 0.11-0.66 (mg DMA-N/ 100g muscle) and 0.36-0.66 (mg TMA-N/ 100g muscle); values obtained for methylamine were in all cases under $0.14 \mathrm{mg}$ MMA-N/ $100 \mathrm{~g}$ muscle. It could be concluded that, in spite of preserving the fish at a relatively low temperature, some formation of deteriorative amines was evident.

Evolution of the PL fraction in frozen $\left(-20^{\circ} \mathrm{C}\right)$ wild coho salmon dorsal muscle was examined (Braddock \& Dugan, 1972). Changes were related to specific hydrolysis of this lipid group by lipolytic enzymes present in the tissue. Thus, a decrease in the total PL content with increasing storage time was apparent. Significant decreases in some PL classes (phosphatidylethanolamine, PE; phosphatidylcholine, PC; lysophosphatidylcholine, LPC) occurred after 6 months of frozen storage, being the decrease higher for PC content than for PE one; contrary, an increase in the lysophosphatidylethanolamine (LPE) fraction presence was obtained. The effect of the frozen storage on the fatty acid composition in the total PL and TG was also analysed in this research (Braddock \& Dugan, 1972). Thus, only minor changes in the fatty acid composition of the TG during a storage period of over 1 year at $-20{ }^{\circ} \mathrm{C}$ was observed, being C 18:1 $\omega 9$, C 22:6 $\omega 3, \mathrm{C} 16: 1 \omega 7$ and $\mathrm{C}$ 16:0 the most abundant fatty acids. Meantime, the analysis of the fatty acid composition of the different PL classes (PE, PC, LPC and LPE) showed that a preferential hydrolysis of PE containing C 16:0, C 18:1 $\omega 9$ and C 22:6 103 fatty acids was implied from fatty acid analyses, so that $\mathrm{C}$ 16:0 and $\mathrm{C}$ 22:6 $\omega 3$ fatty acids were more concentrated and the C 18:1 $\omega 9$ fatty acid was less concentrated in the remaining LPE. Results obtained were explained as a result of the activity of endogenous enzymes under the present frozen conditions and also by means 
of the reactions of the PE amino group with carbonyl compounds known to be produced in the flesh as a result of lipid oxidation development.

Quality changes in coho salmon steaks stored at both constant $\left(-18{ }^{\circ} \mathrm{C}\right)$ and fluctuating (from $-18{ }^{\circ} \mathrm{C}$ to $-4{ }^{\circ} \mathrm{C}$ and then returned to $-18{ }^{\circ} \mathrm{C}$; the cycle was completed in four hours) temperatures were studied; the use of vacuum packaging with or without the addition of antioxidants was also evaluated (Yu, Sinnhuber \& Crawford, 1973). Results of sensory evaluation (texture, juiciness, flavour and overall desirability) showed that the control sample (low density polyethylene bag packaging) became unacceptable after 9 months at constant $-18{ }^{\circ} \mathrm{C}$. According to sensory assessment and peroxide determination, the vacuum-packed samples were judged desirable and of good quality at month 12 . It could be concluded that the shelf life of frozen coho salmon steaks could be extended substantially by vacuum packaging of the fish in low oxygen permeable film. Storage temperature fluctuations were found to cause severe quality damage to the fish, although damage inflicted could be lessened by applying vacuum packaging with and without the presence of antioxidants.

The mechanism of interaction compound formation between lipid oxidation products and aminated compounds (namely, protein-like compounds) was investigated in frozen wild coho salmon (Braddock \& Dugan, 1973). For it, extracts from freezedried and frozen coho salmon $\left(-20{ }^{\circ} \mathrm{C}\right.$ for one year) were compared to model systems consisting of sodium linoleate and coho salmon myosin under buffer $(\mathrm{pH}=7.5)$ solution. According to spectral (IR, UV-Visible and fluorescence) studies and TBA values evolution, the presence of $\mathrm{C}=\mathrm{N}$ groups in the extracts and myosin-containing systems was detected; such groups were absent when considering model systems without myosin (control system). Additionally, significant decreases in nucleophilic amino acids such as histidine, lysine and methionine were found, while PL hydrolysis 
was also shown to occur in frozen muscle. The research presented evidence indicating that production of $\mathrm{C}=\mathrm{N}$ compounds occurred as a result of reaction between oxidation products of the PUFA and amino groups present in the fish muscle.

The effects of freezing rate (slow or fast) and frozen storage time (up to 12 months) on thaw drip formation in wild coho salmon were determined (Bilinski, Jonas, Lau \& Gibbard, 1977). Thaw drip was significantly higher in slow than in fast frozen fish and this difference showed a progressive increase with time of frozen storage. It was concluded that freezing speed is a quantitatively important factor in influencing weight losses of coho salmon during thawing.

Enzymatic PL decomposition of farmed coho salmon during storage at $-5{ }^{\circ} \mathrm{C}$ for 14 days was studied in order to get a better understanding of the PL hydrolysis system in this species (Ohshima, Wada \& Koizumi, 1985). For it, thin layer chromatography, densitometry and HPLC were applied. It could be observed that only small amounts of LPC and LPE would accumulate in its flesh. It was concluded that coho salmon would belong to the lysophospholipid non accumulative-type fish, according to its endogenous phospholipase and lysophospholipase systems.

The effect on protein hydrolysis of partially frozen (or superchilled) wild coho salmon up to 25 days was studied (French, Kramer \& Kennish, 1988). For it, salmon steaks were vacuum packed and held at $0,-1,-2$, and $-3^{\circ} \mathrm{C}$ under refrigerated sea water conditions; control fish was kept under $-20^{\circ} \mathrm{C}$. Protease hydrolysis of individual soluble proteins was analysed by employing SDS-PAGE. Significant changes were observed in different protein bands, being obtained the highest rates of hydrolysis development in fish held at -2 and $-3{ }^{\circ} \mathrm{C}$. A $35 \mathrm{kDa}$ protein band appeared with a half-time of 5 days and then disappeared. Major changes were observed in 34 and $36 \mathrm{kDa}$ bands, half of 
which were hydrolysed in 7-20 days. A $32 \mathrm{kDa}$ protein was very slowly hydrolysed in 14-23 days.

The overall quality (sensory, microbiological and chemical indices) of wild coho salmon during frozen storage $\left(-23^{\circ} \mathrm{C}\right)$ was studied (Barnett, Nelson \& Poysky, 1991); the effect on quality of a previous delay of 7 days in ice was also achieved. After six months of storage, both kinds of fish (with and without previous ice storage) were qualified as premium grade. Between 6 and 12 months, a significant decline of normal sensory attributes occurred in both products, sufficient enough to change their premium quality status to fair; at month 12 , quality of previously iced fish was found lower than its corresponding fish not stored. A good correlation of sensory scores was found with the chemical assessment of rancidity development (TBA value); in advanced stages of frozen storage, an increased effect of oxidative rancidity was observed on overall acceptability. Concerning physical analyses, an increased drip loss was found in all fish as a result of increasing the storage time; an increasing thaw drip loss was also observed in previously iced fish.

4-Hydroxy-2-nonenal (HNE) is a known lipid oxidation compound that may be formed by peroxidation of $\omega 6$ unsaturated fatty acids and exhibits various cytopathological and mutagenic effects. Its assessment in frozen $\left(1\right.$ month at $\left.-80{ }^{\circ} \mathrm{C}\right)$ coho salmon as a 2,4-dinitrophenylhydrazine derivative was achieved (Sakai \& Kuwazuru, 1995). The HNE concentration recorded (2.18-9.39 nmol/ g muscle) was approximately linearly related to TBA value in the fish. It was stated that HNE content in coho salmon was much lower than literature data for beef or pork meats when kept under similar conditions; such low HNE content was attributed to a relatively lower content on $\omega 6$ unsaturated fatty acids. 
Free histidine is known to be converted into histamine as a result of bacteria proliferation, being histamine responsible for the so called "scombroid poisoning". Histamine production in coho salmon muscle by inoculation of Morganella morganii isolated from mackerel (Scomber japonicus) was monitored during storage at different temperatures $\left(-30,-20,4,15,25\right.$ and $\left.37^{\circ} \mathrm{C}\right)$ up to 72 hours (Kim, Price, Morrisey, Field, Wei \& An, 2002). At elevated temperatures, histamine was shown to be produced to levels above the Food and Drug Administration (USA) guideline, being the optimal temperature for histamine formation $25^{\circ} \mathrm{C}$. Bacterial growth (total aerobics) was shown to be controlled by cold storage of the fish at $4{ }^{\circ} \mathrm{C}$ or below, but histamine formation was controlled only by frozen storage. Although histamine was not detected in any frozen samples, it showed to accumulate rapidly in fish that had been previously frozen when stored at $25^{\circ} \mathrm{C}$.

Lipid changes related to quality loss were evaluated during frozen storage ( -20 ${ }^{\circ} \mathrm{C}$ ) of farmed coho salmon for up to 15 months (Rodríguez et al., 2007). Biochemical indices concerning lipid hydrolysis (FFA) and oxidation (peroxide value; TBA value; FR; polyene index) were determined and compared to sensory (aroma and flavour) acceptance and endogenous antioxidant (tocopherol isomers and AX) content. As a result of frozen storage, lipid hydrolysis was shown to develop according to the increase in FFA content. However, most biochemical lipid oxidation indices (peroxide value, TBA index and FR) led to a low degree of rancidity development when compared to other fatty fish species under similar frozen storage conditions. The polyene index decreased at month 10 but then remained unchanged until the end of the experiment. Rancid odour and flavour development were shown to be low throughout the experiment, according to the biochemical indices mentioned above. However, a progressive score decrease in the original fresh odour and flavour of salmon fish flesh 
occurred with increasing frozen storage time, such that fish samples had the poorest values by month 15 . Endogenous antioxidant contents were remarkably stable throughout the experiment, this being very likely to contribute to the oxidative stability of frozen farmed coho salmon lipids.

A commercial diet including synthetic antioxidants (butylated hydroxytolueneethoxyquin mixture; diet 1) was provided to coho salmon in parallel with two diets including natural antioxidants (tocopherol isomers-rich mixture, diet 2; tocopherol isomers-rosemary extract mixture, diet 3) (Ortiz et al., 2009). A comparative study of the rancidity development in the corresponding frozen $\left(-18{ }^{\circ} \mathrm{C}\right)$ products was undertaken. When compared to fish fed with diet 1 , individuals corresponding to diets 2 and 3 showed a greater retention of primary (conjugated dienes and peroxides content) and secondary (anisidine and TBA values) lipid oxidation compounds that led to a lower FR (Figure 2); likewise, a higher polyene index and lower oxidised taste scores were obtained for fish samples corresponding to diet 2. No effect on lipid hydrolysis development (FFA formation) could be found as a result of employing different diets.

An advanced packaging combining a polyphenol rich-film and vacuum (PPRFVP) was applied to farmed coho salmon for a 18 month-storage $\left(-18^{\circ} \mathrm{C}\right)$ period (Rodríguez, Cruz, Paseiro \& Aubourg, 2011); comparison to vacuum control and polyethylene control packaging conditions was carried out. The study was addressed to hydrolytic and oxidative changes related to fish rancidity development and to lipid changes related to nutritional value. PPRF-VP condition provided an inhibitory effect on conjugated diene and fluorescent compound (FR) formation in frozen salmon. Compared to polyethylene control condition, vacuum packaging (PPRF-VP and vacuum control conditions) led to lower peroxide and anisidine values and to an inhibitory effect on $\alpha$ - and $\gamma$-tocopherol losses during storage. No effect of polyphenol presence and 
vacuum packaging could be inferred on FFA formation and PUFA retention. A low rancid odour development was observed in all kinds of fish samples, this being lower in fish kept under vacuum (PPRF-VP and vacuum control) conditions.

\subsection{Canned products}

Largely through tradition, colour has been an important consumer criterion of quality in canned salmon. According to this importance, Bolton, Mann and Gushue (1967) proposed the employment of a standardised colour surface grading susceptible to be applied in all species belonging to the common name "Pacific salmon" (O. nerka, O. keta, O. gorbusha, O. tshaytscha and O. kisutch). For it, measurement of red, green and blue stimuli by chromaticity coordinates, according to the C.I.E. (Commission Internationale de l'Éclairage) methodology, were recommended to be measured.

Different collaborative studies were carried out to identify the canned salmon species, based on the scale analysis (Newton, 1979). As a result, a method was proposed for identifying chum (O. keta), sockeye (O. nerka), coho (O. kisutch), chinook (O. tshawytscha) and pink (O. gorbusha) salmon by wide-field microscope analysis of their scales (AOAC, 1990).

Traditional attempts to reduce or eliminate curd associated with the canning of salmon consisted on prior immersion of fish segments in some aqueous solutions to remove coagulable proteins; among the most employed, tartaric acid, disodium dipicolinate and urea solutions can be mentioned. With the aim of performing this pretreatment, Yamamoto and Mackey (1981) proposed a different method consisting on applying an aqueous extract of papaya latex powder to the surface of raw coho salmon segments prior to conventional vacuum sealing and heat sterilisation; it was based on the fact that large curd-forming proteins, once reduced to peptide and polypeptide 
fragments, would no longer coagulate when heated, thus obtaining a substantial reduction in curd formation. This addition was successfully applied on sockeye $(O$. nerka) and coho (O. kisutch) salmon.

It has been reported that ethanol content in canned salmon would be highly correlated to the sensory score of the product. Consequently, a rapid and simple method using a headspace sampling technique and gas chromatographic detection was developed for the analysis of ethanol in canned coho salmon (Hollingworth \& Throm, 1983). A highly significant correlation between ethanol content and sensory classification in canned coho salmon was confirmed in this study; in addition, it was found that the relationship had potential practical application for the confirmation of an initial sensory classification of the raw material employed for canning.

The effect of sexual maturation of coho salmon fish on the quality of the corresponding canned product was studied (Bilinski, Jonas, Peters \& Chromanski, 1984). For it, changes in chemical composition of the flesh of coho salmon during its progressive sexual maturation in a fresh water hatchery (middle July-middle November) were studied in relation to its quality when canned. Sexual maturation caused a depletion ( $\mathrm{g} / 100 \mathrm{~g}$ muscle) of fat (5.8 to 2.0) and protein (22.1 to 17.3) from the flesh with a concurrent increase in moisture (70.4 to 79.5). The non-protein nitrogen content of raw flesh remained fairly constant but FFA content showed a significant increase. Related to sensory appreciation, progressive sexual maturation produced a canned product showing increase in free liquid, decrease in free oil and curd, discoloration and softening of flesh, and deterioration of flavour and odour. A significant correlation between moisture content of raw flesh and the final quality of canned salmon was observed; it was suggested that moisture content of raw flesh would be of potential 
value as a quality indicator to determine the acceptability of salmon for canning during progressive increase in sexual maturity.

Volatile compounds responsible for sockeye (O. nerka) and coho (O. kisutch) salmon flavour were investigated and the role of carotenoid pigments in the development of cooked and canned salmon flavours was examined (Josephson, Lindsay \& Stuiber, 1991b). The study was also directed towards defining the chemical mechanisms involved in the generation of aroma compounds which contributed strongly to the characteristic flavour of cooked salmon. It could be observed that volatile compounds associated with fresh-baked and baked-canned salmon flavours were different, but each exhibited distinct salmon-loaf-like aroma and contained a single compound exhibiting the aroma. Model systems employing intact salmon oil adsorbed onto Celite supports were developed to produce cooked salmon-loaf-like aromas for studies on the mechanism of aroma formation. As a result, salmon-based carotenoids appeared either to serve as the direct precursor compounds to salmon-loaf-like aroma or modulate chemical reactions which convert fatty acid or other lipid precursors to a salmon-loaf-like aroma compound.

Multivariate statistical analyses were applied to 44 volatile compounds measured by static headspace gas liquid chromatography with the aim of differentiating between four species of canned Pacific salmon, namely chum (O. keta), coho (O. kisutch), pink (O. gorbuscha), and sockeye (O. nerka) (Girard \& Nakai, 1993). Using principal component analysis as a data reduction technique, the first ten principal components were retained and explained $87 \%$ of total variation in the data. Results indicated that volatile compounds handled by principal component analysis followed by nonparametric discriminant analysis would constitute an efficient technique for 
differentiating salmon species to determine the identity of unknown or doubtful canned samples.

Fatty acid composition and cholesterol content were determined in different commercial canned coho salmon (Romero, Robert, Masson, Luck \& Buschmann, 1996). Total PUFA content accounted for $35.1 \%$ of total fatty acids. Values obtained for C 20:5 $\omega 3, \mathrm{C} 22: 6 \omega 3$, total $\omega 3$ and cholesterol were (mg/ $100 \mathrm{~g}$ muscle): $531 \pm 159,1163$ $\pm 262,2725 \pm 680$ and $60 \pm 10$, respectively. The main $\omega 6$ fatty acid was C 20:4 $\omega 6(2.6$ $\pm 0.3 \%$ of total fatty acids). It was concluded that canned coho salmon would be a valuable source of $\omega 3$ PUFA.

Farmed coho salmon was studied as a raw material to be employed for the canning process (Rodríguez, Carriles, Gallardo \& Aubourg, 2009). The effects of preliminary chilling storage and thermal treatment (cooking and sterilisation) on the chemical constituents (lipids and non-protein nitrogen compounds) of the canned fish were analysed. An increasing previous chilling time led to an important autolysis ( $\mathrm{K}$ value) development, and to an increasing formation of FFA and interaction compounds (FR and browning assessments) in the canned product. The thermal treatment led to the formation of volatile amines (total and TMA), FFA, secondary lipid oxidation compounds (anisidine and TBA values) and interaction compounds in canned fish. Interaction compound assessment was found the most useful tool to study the lipid oxidation and non-enzymatic browning developments, while the $\mathrm{K}$ value showed to be an interesting index for assessing the freshness stage of the raw material employed.

The comparative effect of flake ice and slurry ice as previous slaughter and chilling conditions on sensory and physical properties of canned farmed coho salmon was studied (Rodríguez, Carriles \& Aubourg, 2010); hydrolytic chemical changes related to sensory and physical properties were also evaluated. Thermal treatment led to 
a canned muscle showing higher firmness, lower cohesivity and colour changes (higher $\mathrm{L}^{*}$ and $\mathrm{b}^{*}$ values; lower $\mathrm{a}^{*}$ values); filling oils showed higher turbidity scores and lower $\mathrm{L}^{*}, \mathrm{a}^{*}$ and $\mathrm{b}^{*}$ values than starting oil. Additionally, oxidized and putrid odour development in canned muscle and filling oil was low. However, previous icing condition and time (up to 9 days) provided no changes in canned muscle and filling oil, except for an increasing oxidized odour and turbidity in filling oil with chilling time. Meantime, FFA formation and K value were greatly affected by previous icing system and time.

\subsection{Other thermally-treated products}

The effect of sodium tripolyphosphate (TPP) in controlling the loss of moisture from smoked coho salmon was investigated (Barnett et al., 1969). The fish were stored at $-23{ }^{\circ} \mathrm{C}$, thawed for 48 hours at $1-2^{\circ} \mathrm{C}$ and cut into $170-227 \mathrm{~g}$ pieces with skin being retained on one side. Three treatments were applied: (i) soaking for $1 \mathrm{~h}$ in concentrated brine, (ii) dipping for $1 \mathrm{~min}$ in a solution containing $7.5 \% \mathrm{TPP}$ and $2 \% \mathrm{NaCl}$, and (iii) soaking for 1 hour in a concentrated brine solution containing $2 \%$ TPP. The fish were then smoked for 14 hours at a temperature of $21^{\circ} \mathrm{C}$, being hot smoked at a temperature of $113{ }^{\circ} \mathrm{C}$ during the final hour. As a result, TPP presence was shown to be effective in reducing the loss of weight, being treatment (iii) the most effective.

A study was conducted to determine if organoleptic differences among species of salmon raised in fresh and salt water could be detected by a trained sensory panel and to determine consumer preference according to the evaluation of a consumer panel (Ostrander, Martinsen, Liston \& McCullough, 1976). As a result, the trained panel determined differences of baked samples on odour, texture, moistness and flavour and visual differences for flesh colour, fibre structure, and brownness along the lateral line. 
Highly significant differences were detected among samples for texture, flavour, colour, and fibre structure. Contrary, consumer evaluation of salmon samples indicated no significant differences in preference among the samples. However, typical salmon flavour seemed to be absent from these fish, this suggesting that aquaculturists should pay great attention to the organoleptically desirable features of the fish they raise.

Fatty acid composition was studied by GLC in commercial smoked coho salmon TG (Renon, Cantoni \& Comi, 1978). Major fatty acids (g/ 100g total fatty acids) found were C 18:1 (18.6), C 22:6 (13.8), C 20:5 (12.0) and C 16:0 (10.2) ( $\omega$ series were not elucidated), being total PUFA content evaluated as $71.7 \%$ of total fatty acids.

Free amino acid and related compounds have shown to exert an important effect on flavour properties in fish products. Related to this, composition and content of such non-protein group in $80 \%$ aqueous ethanol extract from heated (40 minutes in boiling water) coho salmon muscle were analysed (Shirai et al., 1983a). According to the water content loss produced by the heating process, the amounts of total extractive nitrogen in the heated muscles were remarkably higher than those in the raw muscles (461-462 versus 363-365 mg N/ 100g muscle, respectively). Most remarkable values found in heated muscle consisted on relatively high values on anserine and serine (542-587 and $11 \mathrm{mg} / 100 \mathrm{~g}$ muscle, respectively).

Zottola, Wagner and Zoltai (1983) studied the chemical composition and microbiology activity of some native Alaskan preserved foods. One of them was halfsmoked wild coho salmon. For it, the fish was brined and then smoked in the smokehouse for 1 day only; then, before consumption, it was heated for 2 hours in a hot air oven. For this half-smoked product, values obtained (g/ 100g muscle) were: 1.8 (salt), 19.5 (protein) and 23.2 (lipids). Microbiological results indicated that the process used did not destroy spores, and that potential hazards from Clostridia and other 
anaerobic microorganisms may exist if products were stored at a temperature higher than $3{ }^{\circ} \mathrm{C}$.

The possibility of enlarging the shelf life time of smoked salmon by employment of modified atmospheres was investigated (Civera, Amerio \& Parisi, 1993). For it, sliced smoked coho salmon was packaged under three modified atmospheres: i) $70 \%$ $\mathrm{CO}_{2} / 25 \% \mathrm{~N}_{2} / 5 \% \mathrm{O}_{2}$, ii) $95 \% \mathrm{CO}_{2} / 5 \% \mathrm{O}_{2}$, and iii) $60 \% \mathrm{CO}_{2} / 25 \% \mathrm{O}_{2} / 15 \% \mathrm{~N}_{2}$. Samples were stored at $2-3{ }^{\circ} \mathrm{C}$ for up to 120 days, being fish muscle analysed for microbiological activity by microbiological (counts on different bacterial groups) and chemical (volatile amine formation) quality indices. Growth of spoilage bacteria was found to be markedly inhibited by $\mathrm{CO}_{2}$-rich atmospheres and by growth of lactic acid bacteria. Quality retention was best for samples packaged in the $70 \% \mathrm{CO}_{2}$ atmosphere, since $95 \% \mathrm{CO}_{2}$-atmosphere increased volatile amine formation, whereas the $60 \%$ $\mathrm{CO}_{2}$-atmosphere resulted in the development of a slight sour odour after 15 days. With the optimum modified atmosphere, shelf life obtained was included in the 90-100-day range.

A comparative study focused to PUFA retention in wild coho salmon products was achieved (Bower, Malemute \& Oliveira, 2007). For it, fish fillets were processed using five different methods (smoking, canning, freezing, acidifying and salting) to evaluate the effect of the preservation choice on the quality of PUFA. Salmon muscle preserved by smoking, canning or freezing was found to retain higher values of total fatty acids, including $\omega 3$ PUFA such as C 20:5 $\omega 3$ and C 22:6 $\omega 3$. Salting and acidifying treatments resulted in a significant decrease in PUFA content.

Farmed coho salmon were slaughtered in slurry ice $\left(-1.5^{\circ} \mathrm{C}\right)$ and then stored in this medium for further processing after 0, 5 and 9 days (Rodríguez, Carriles, Cruz \& Aubourg, 2008). For it, the fish were cooked whole and the flesh was evaluated by 
sensory, physical and chemical techniques to establish if significant changes had occurred as a result of the previous chilled storage period. Initial samples from harvest were also evaluated for comparison. There was evidence of increases in TMA, lipid hydrolysis, lipid oxidation (anisidine and TBA values) and interaction compound formation (FR and browning measurements) as a result of the cooking process and previous chilling time (Figure 3). The fish structure became more breakable with longer previous storage but there were no changes in sensory assessments for rancid and putrid odours, so that scores were less than 0.5 on a 11 -point scale. It was concluded that primary and secondary lipid oxidation development and further interaction compound formation appeared to be the main measurable indicators of quality changes in cooked coho salmon. However, and according to sensory appreciation, slurry ice showed to be a suitable medium for previous storage of coho salmon for periods of up to 9 days.

\section{RECOMMENDED FUTURE RESEARCH}

Coho salmon has shown to provide a profitable raw material composition to be included in the human diet as such, or in combination with other food components. In agreement to the actual depletion of many wild fish species, present and future of coho salmon commercialisation is specially turned into its farming development and employment. Accordingly, it is advisable that future research is aimed to this kind of fish, taking into account activity areas as the following ones:

Chemical composition assessment: A strong effect of diet composition applied and of living cycle maturation stage of individuals at the slaughtering step has been recognised 
for all farmed fish species. Consequently, a wider knowledge of both effects on the different chemical constituent presence ought to be acquired, this specially taking into account important compounds such as essential amino acids and microelements, vitamins and fatty acids belonging to the $\omega 3$ series. Such knowledge would be necessary if coho salmon is to enter a multi-component or "ready-to-eat" food, so that a concrete content of such valuable constituents is expected to be provided to the resulting food.

Employment in traditional product manufacture: Aquatic species as a whole constitute very labile products since different damage pathways can develop (endogenous enzyme activity, microbiological activity, non-enzymatic lipid oxidation and browning, and enzymatic browning) during the technological treatment. It is well known that commercial processes which include relatively strong conditions, such as the thermal ones (cooking, canning, smoking, etc.), need to start from high quality raw material. In this case, the employment of farmed coho salmon instead of wild fish is greatly recommended; corresponding research ought to focus the optimization of the slaughtering and previous storage steps.

Application of advanced technologies: Assurance of both safety and quality (sensory and nutritional) of seafood is an important actual challenge. In order to inhibit the different mechanisms responsible for coho salmon deterioration during processing and/or storage, efficient processing techniques must be employed. When fresh coho salmon is to be commercialized, modified atmosphere, vacuum packaging, irradiation treatments and binary systems can constitute a good choice to prolong the shelf life time. When a frozen product is encountered, attention should be specially accorded to lipid oxidation development, so that the employment of antioxidants (replacement of 
synthetics by naturals), cryoprotectants, and edible and intelligent coatings and films can provide profitable possibilities. Finally, when a thermally treated coho salmon product is to be commercialized, accurate time/ temperature conditions ought to be employed, so that the retention degree of most fish constituents remains at an acceptable level; employment of "sous-vide" cooking concerning the employment of additional hurdles and optimization strategies and process control by computer are being investigated and their practice is now encouraged.

Employment of off-products: Fish offals produced by preliminary processing are normally used for meal, oil, silage and feed elaboration. Depending on the preliminary treatment applied to the fish, offals include various inedible parts, such as viscera, heads, cut-offs, bones and skin. Related to coho salmon, research ought to be aimed at employing its offals as raw material to yield components such as collagen/ gelatine, bioactive peptides, enzymes, lipids (namely, $\omega 3$ fatty acids), essential amino acids, microelements, etc.

\section{Acknowledgements}

The authors thank the support provided by the Universidad de Chile (Chile)Consejo Superior de Investigaciones Científicas (CSIC, Spain) research program through the following projects: Project 2003 CL 0013, Project 2004 CL 0038 and Project 2006 CL 0034. 


\section{ABBREVIATIONS LIST}

ATP: $\quad$ adenosine triphosphate

AX: $\quad$ astaxanthin

CX: canthaxanthin

DMA: dimethylamine

DNA: deoxyribonucleic acid

FFA: $\quad$ free fatty acids

FR: $\quad$ fluorescence ratio

GLC: $\quad$ gas liquid chromatography

GSH: glutathione

GSSG: glutathione disulphide

HHP: $\quad$ hydrostatic high pressure

HNE: 4-hydroxy-2-nonenal

HPLC: $\quad$ high performance liquid chromatography

HX: hypoxanthine

IMP: $\quad 5$ '-inosine monophosphate

LPC: lysophosphatidylcholine

LPE: lysophosphatidylethanolamine

MMA: monomethylamine

MUFA: monounsaturated fatty acids

PAGE: polyacrylamide gel electrophoresis

PC: phosphatidylcholine

PCR: $\quad$ polymerase chain reaction

PCS: $\quad$ principal component similarity 
PE: phosphatidylethanolamine

PL: $\quad$ phospholipids

PPRF-VP: polyphenol rich-film and vacuum packaging

PUFA: $\quad$ polyunsaturated fatty acids

RFLP: $\quad$ restriction fragment length polymorphism

SDS: $\quad$ sodium dodecyl sulphate

TAM: $\quad$ total aerobic mesophiles

TBA thiobarbituric acid

TG: $\quad$ triglycerides

TMA: trimethylamine

TPP: $\quad$ tripolyphosphate 


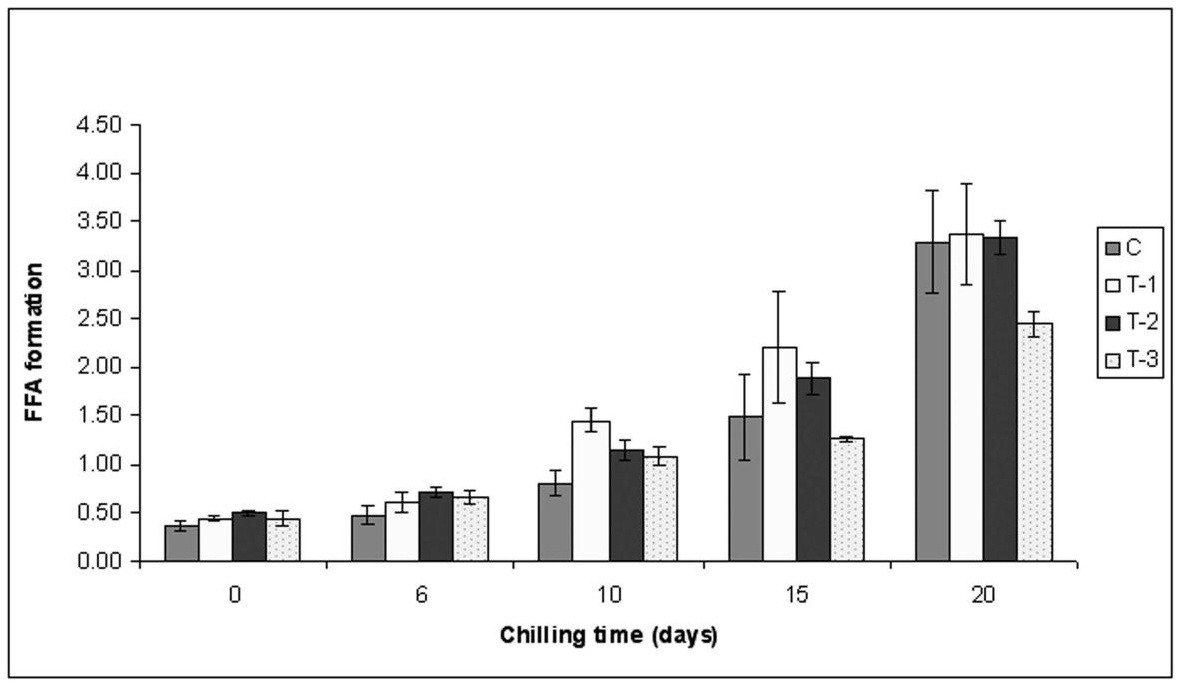




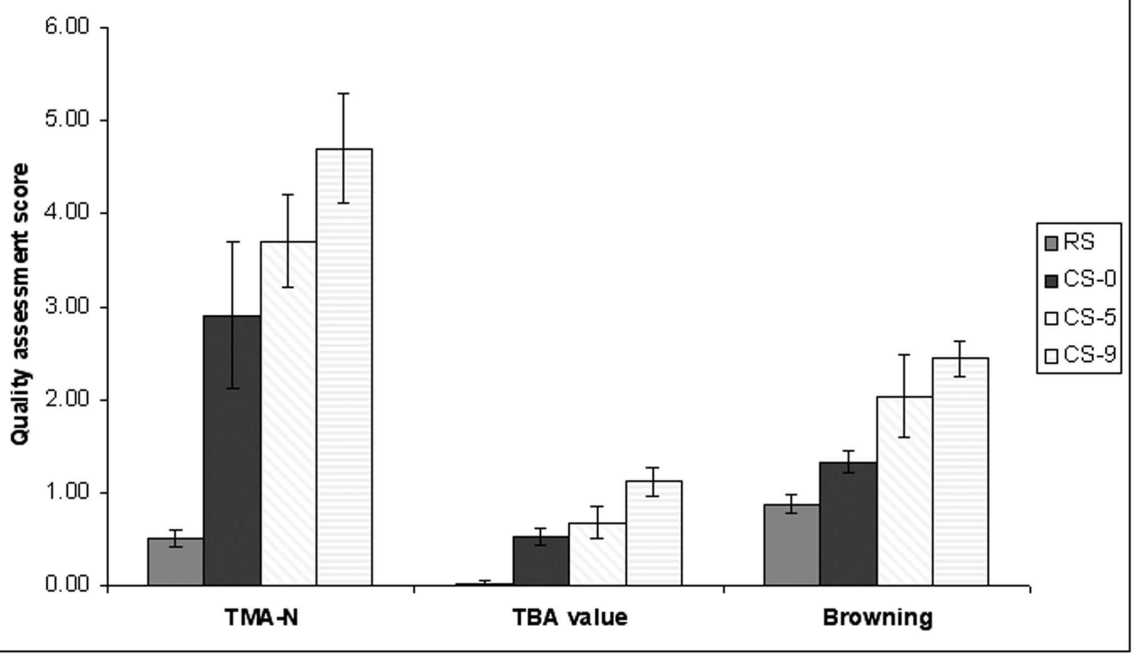




\section{REFERENCES}

AOAC (1990). Identification of canned Pacific salmon. Microscopic method. In K. Helrich (Ed.), Official Methods of Analysis (15 ${ }^{\text {th }}$ edition) (p. 889), vol. 2. Arlington, VA, USA: Association of Official Analytical Chemists Inc.

Aubourg, S. (2008). Practices and processing from catching or harvesting till packaging: Effect on canned product quality. In A. G. Cabado, \& J. M. Vieites (Eds.), Quality Parameters in Canned Seafoods (pp. 1-24). New York, USA: Nova Science Publishers, Inc.

Aubourg, S., Quitral, V., Larraín, Ma A., Rodríguez, A., Gómez, J., Maier, L., \& Vinagre, J. (2007). Autolytic degradation and microbiological activity in farmed Coho salmon (Oncorhynchus kisutch) during chilled storage. Food Chemistry, $104,369-375$.

Aubourg, S., Tabilo-Munizaga, G., Reyes, J., Rodríguez, A., \& Pérez-Won, M. (2010). Effect of high pressure treatment on microbial activity and lipid oxidation in chilled coho salmon. European Journal of Lipid Science and Technology, 112, $362-372$.

Aubourg, S., Vinagre, J., Rodríguez, A., Losada, V., Larraín, $\mathrm{M}^{\mathrm{a}}$ A., Quitral, V., Gómez, J., Maier, L., \& Wittig, E. (2005). Rancidity development during the chilled storage of farmed Coho salmon (Oncorhynchus kisutch). European Journal of Lipid Science and Technology, 107, 411-417.

Barnett, H., Nelson, R., \& Dassow, J. (1969). Use of sodium tripolyphosphate to control fish shrinkage during hot-smoking. Fishery Industrial Research, 5, 103-106.

Barnett, H., Nelson, R., \& Poysky, F.(1991).A comparative study using multiple indices to measure changes in quality of pink and Coho salmon during fresh and frozen 
storage. http://www.nwfsc.noaa.gov/publications/techmemos/tm208/tm208.pdf). NOAA Technical Memorandum NMFS F/NWC-208. U. S. Department of Commerce.

Bilinski, E., Jonas, R., Lau, Y., \& Gibbard, G. (1977). Treatments before frozen storage affecting thaw drip formation in Pacific salmon. Journal of the Fisheries Research Board of Canada, 34, 1431-1435.

Bilinski, E., Jonas, R., Peters, M., \& Chromanski, E. (1984). Effects of sexual maturation on the quality of coho salmon (Oncorhynchus kisutch) flesh. Canadian Institute of Food Science and Technology Journal, 17, 271-273.

Bolton, R., Mann, J., \& Gushue, W. (1967). Use of standardized colour surfaces in the grading of canned salmon for colour. Journal of the Fisheries Research Board of Canada, 24, 1613-1622.

Bower, C., Malemute, C., \& Oliveira, A. (2007). Preservation methods for retaining n-3 polyunsaturated fatty acids in Alaska coho salmon (Oncorhynchus kisutch) products. Journal of Aquatic Food Product Technology, 16, 45-54.

Braddock, R., \& Dugan, L. (1969). Fatty acids of lake Michigan coho salmon. Journal of the American Oil Chemists' Society, 46, 428-428.

Braddock, R., \& Dugan, L. (1972). Phospholipid changes in muscle from frozen stored lake Michigan Coho salmon. Journal of Food Science, 37, 426-429.

Braddock, R., \& Dugan, L. (1973). Reaction of autoxidizing linoleate with coho salmon myosin. Journal of the American Oil Chemists’ Society, 50, 343-347.

Brown, D., Albright, M., Watts, D., Heyer, B., Spruce, B., \& Price, R. (1980). Modified atmosphere storage of rockfish (Sebastes miniatus) and silver salmon (Oncorynchus kisutch). Journal of Food Science, 45, 93-96. 
Civera, T., Amerio, G., \& Parisi, E. (1993). Shelf-life of sliced smoked, salmon packaged with different modified atmospheres: experimental results. Industrie Alimentari, 32, 705-714.

Coduri, R., Bonatti, K., \& Simpson, K. (1979). Application of vertical plate gel electrophoresis to the separation of pigmented and non-pigmented trout and salmon species. Journal of the Association of Official Analytical Chemists, 62, 269-271.

Dosanjh, B., Higgs, D., Plotnikoff, D., McBride, J., Markert, J., \& Buckley, J. (1984). Efficacy of canola oil, pork lard and marine oil singly and in combination as supplemental dietary lipid sources for juvenile coho salmon (Oncorhynchus kisutch). Aquaculture, 36, 333-345.

FAO Inform (2007a). Fishery statistics. Aquaculture Production, yearbook 2005 (Vol. 100/2, p. 73). Rome, Italy: Food and Agriculture Organization of the United Nations.

FAO Inform (2007b). Fishery statistics. Capture Production, yearbook 2005 (Vol. 100/1, p. 79). Rome, Italy: Food and Agriculture Organization of the United Nations.

French, J., Kramer, D., \& Kennish, J. (1988). Protein hydrolysis in coho and sockeye salmon during partially frozen storage. Journal of Food Science, 53, 1014-1017, 1029.

Girard, B., \& Nakai, S. (1993). Species differentiation by multivariate analysis of headspace volatile patterns from canned Pacific salmon. Journal of Aquatic Food Product Technology, 2, 51-68.

Gruger, E. (1972). Chromatographic analyses of volatile amines in marine fish. Journal of Agricultural and Food Chemistry, 20, 781-785. 
Gruger, E., Nelson, R., \& Stansby, M. (1964). Fatty acid composition of oils from 21 species of marine fish, freshwater fish and shellfish. Journal of the American Oil Chemists' Society, 41, 662-667.

Hardy, R., \& King, I. (1989). Variation in n-3 fatty acid content of fresh and frozen salmon. Omega 3 News. Unsaturated Fatty Acids and Health, 4, 1-4.

Hata, M., Sato, Y., Yamaguchi, T., Ito, M., \& Kuno, Y. (1988). The chemical and amino acid compositions in tissues of cultured and wild coho salmon Oncorhynchus kisutch. Bulletin of the Japanese Society of Scientific Fisheries, $54,1365-1370$.

Henmi, H., Hata, M., \& Hata, M. (1989). Astanxanthin and/ or cantaxanthin-actomyosin complex in salmon muscle. Bulletin of the Japanese Society of Scientific Fisheries, 55, 1583-1589.

Henmi, H., Hata, M., \& Hata, M. (1990). Studies on the carotenoids in the muscle of salmon. III. Combination of astaxanthin and canthaxanthin with fish muscle actomyosins associated with their surface hydrophobicity. Bulletin of the Japanese Society of Scientific Fisheries, 56, 1821-1823.

Henmi, H., Iwata, T., Hata, M., \& Hata, M. (1987). Studies on the carotenoids in the muscle of salmons. I. Intracellular distribution of carotenoids in the muscle. Tohoku Journal of Agricultural Research, 37, 101-111.

Heu, M-S, \& Ahn, S-H. (1999). Development and fractionation of proteolytic enzymes from an inedible seafood product. Journal of the Korean Fisheries Society, 32, $458-465$.

Higgs, D., Skura, B., Dosanjh, B., Yan, D., Powrie, W., \& Donaldson, E. (1989). Comparing farmed and wild coho salmon. Canadian Aquaculture, 5, 51-53. 
Hollingworth, T., \& Throm, H. (1983). A headspace gas chromatographic method for the rapid analysis of ethanol in canned salmon. Journal of Food Science, 48, 290-291.

Iverson, J. (1972). Fish and other marine products. Per cent fatty acid composition and quality differences of Chinook and coho salmon. Journal of the Association of Official Analytical Chemists, 55, 1187-1190.

Josephson, D., Lindsay, R., \& Stuiber, D. (1991b). Volatile carotenoid-related oxidation compounds contributing to cooked salmon flavor. Lebensmittel- Wissenschaft und Technologie, 24, 424-432.

Josephson, D., Linsya, R., \& Stuiber, D. (1991a). Influence of maturity on the volatile aroma compounds from fresh Pacific and Great Lakes salmon. Journal of Food Science, 56, 1576-1579, 1585.

Karrick, N., \& Thurston, C. (1964). Proximate composition of silver salmon. Journal of Agricultural and Food Chemistry, 12, 282-284.

Kemp, B., \& Spinelli, J. (1969). Comparative rates of IMP degradation in unfrozen and frozen-and-thawed (slacked) fish. Journal of Food Science, 34, 132-135.

Kim, S., Price, R., Morrissey, M., Field, K., Wei, C., \& An, H. (2002). Histamine production by Morganella morganii in mackerel, albacore, mahi-mahi, and salmon at various storage temperatures. Journal of Food Science, 67, 15221528.

Luong, J., Male, K., Masson, C., \& Nguyen, A. (1992). Hypoxanthine ratio determination in fish extract using capillary electrophoresis and immobilized enzymes. Journal of Food Science, 57, 77-81.

Markert, J., \& Vanstone, W. (1971). Egg proteins of coho salmon (Oncorhynchus kisutch): Chromatographic separation and molecular weights of the major 
proteins in the high density fraction and their presence in salmon plasma. Journal of the Fisheries Research Board of Canada, 28, 1853-1856.

Mori, T., Okada, S., Yamaguchi, K., Konosu, S., Yamada, Y., Satake, M., Toyoda, K., \& Fujita, T. (1990). Chemistry and utilization of plankton. XXI. Pigmentation of coho salmon cultured in sea net pens with Antarctic krill and littoral mysid. Bulletin of the Japanese Society of Scientific Fisheries, 56, 935-939.

Nakai, S., Wang, Z., Dou, J., Nakamura, S., Ogawa, M., Nakai, E., \& Vanderstoep, J. (1999). Gas chromatography/ principal component similarity system for detection of E. coli and S. aureus contaminating salmon and hamburger. Journal of Agricultural and Food Chemistry, 47, 576-583.

Nettleton, J., \& Exler, J. (1992). Nutrients in wild and farmed fish and shellfish. Journal of Food Science, 57, 257-260.

Newton, R. (1979). Identification of canned salmon species by scale characteristics. Journal of the Association of Official Analytical Chemists, 62, 722-727.

Ohshima, T., Wada, S., \& Koizumi, C. (1985). Accumulation of lyso-form phospholipids in several species of fish flesh during storage at $-5^{\circ} \mathrm{C}$. Bulletin of the Japanese Society of Scientific Fisheries, 51, 965-971.

Ortea, I., Rodríguez, A., Tabilo-Munizaga, G., Pérez-Won, M., \& Aubourg, S. (2010). Effect of hydrostatic high pressure treatment on proteins, lipids and nucleotides in chilled farmed salmon (Oncorhynchus kisutch) muscle. European Food Research and Technology, 230, 925-934.

Ortiz, J., Larraín, MaA., Vivanco, J., \& Aubourg, S. (2009). Rancidity development during the frozen storage of farmed coho salmon (Oncorhynchus kisutch): Effect of antioxidant composition supplied in the diet. Food Chemistry, 115, 143-148. 
Ostrander, J., Martinsen, C., Liston, J., \& McCullough, J. (1976). Sensory testing of pen-reared salmon and trout. Journal of Food Science, 41, 386-390.

Ota, T., Sasaki, S., Abe, T., \& Takagi, T. (1990). Fatty acid compositions of lipids obtained from commercial salmon products. Bulletin of the Japanese Society of Scientific Fisheries, 56, 323-327.

Paterson, B., Goodrick, B., \& Frost, S. (1997). Controlling the quality of aquacultured food products. Trends in Food Science and Technology, 8, 253-257.

Pauly, D., Christensen, V., Guénette, S., Pitcher, T., Sumaila, R., Walters, C., Watson, R., \& Zeller, D. (2002). Towards sustainability in world fisheries. Nature, 418, 689-695.

Perea, A., Gómez, E., Mayorga, Y., \& Triana, C. (2008). Nutritional characterization of produced fish for human consumption in Bucaramanga, Colombia. Archivos Latinoamericanos de Nutrición, 58, 91-97.

Piclet, G. (1987). Le poisson aliment. Composition et intérèt nutritionnel. Cahiers de Nutrition et Diététique, XXII, 317-335.

Rehbein, H., Devlin, R., \& Rüggeberg, H. (2002). Detection of a genetic alteration and species identification of coho salmon (Oncorhynchus kisutch): a collaborative study. European Food Research Technology, 214, 352-355.

Renon, P., Cantoni, C., \& Comi, G. (1978). Fatty acids of smoked salmon. Industrie Alimentari, 17, 509-514.

Roch, M., Tesar, B., \& Patterson, J. (1988). Omega 3 and the farmed fish. Canadian Aquaculture, 4, 49-51, 53.

Rodríguez, A., Carriles, N., \& Aubourg, S. (2010). Effect of chill storage under different icing conditions on sensory and physical properties of canned farmed 
salmon (Oncorhynchus kisutch). International Journal of Food Science and Technology, 45, 295-304.

Rodríguez, A., Carriles, N., Cruz, J. M., \& Aubourg, S. (2008). Changes in the flesh of cooked farmed salmon (Oncorhynchus kisutch) with previous storage in slurry ice $\left(-1.5^{\circ} \mathrm{C}\right)$. Food Science and Technology (LWT), 41, 1726-1732.

Rodríguez, A., Carriles, N., Gallardo, J. M., \& Aubourg, S. (2009). Chemical changes during farmed coho salmon (Oncorhynchus kisutch) canning: Effect of a preliminary chilled storage. Food Chemistry, 112, 362-368.

Rodríguez, A., Cruz, J. M., Paseiro, P., \& Aubourg, S. (2011). Effect of polyphenolic rich-film and vacuum packaging on lipid deterioration during frozen storage of farmed coho salmon (Oncorhynchus kisutch). Food Chemistry. Under revision.

Rodríguez, A., Losada, V., Larraín, Ma A., Quitral, V., Vinagre, J., \& Aubourg, S. (2007). Development of lipid changes related to quality loss during the frozen storage of farmed Coho salmon (Oncorhynchus kisutch). Journal of the American Oil Chemists’ Society, 84, 727-734.

Romero, N., Robert, P., Masson, L., Luck, C., \& Buschmann, L. (1996). Composition in fatty acid and contribution of cholesterol of Chilean jack mackerel, sardine, salmon and tuna in natural fish canned. Archivos Latinoamericanos de Nutrición, 46, 75-77.

Rusell, V., Hold, G., Pryde, S., Rehbein, H., Quinteiro, J., Rey-Méndez, M., Sotelo, C., Pérez-Martín, R., Santos, A., \& Rosa, C. (2000). Use of restriction fragment length polymorphism to distinguish between salmon species. Journal of Agricultural and Food Chemistry, 48, 2184-2188. 
Saddler, J., Lowry, R., Krueger, H., \& Tinsley, I. (1966). Distribution and identification of the fatty acids from the coho salmon, Oncorhynchus kisutch (Walbaum). Journal of the American Oil Chemists' Society, 43, 321-324.

Sakai, T., \& Kuwazuru, S. (1995). A lipid peroxidation-derived aldehyde, 4-hydroxy-2nonenal. Contents in several fish meats. Fisheries Science, 61, 527-528.

Shirai, T., Fuke, S., Yamaguchi, K., \& Konosu, S. (1983a). Amino acids and related compounds in the extracts of heated muscle of four species of salmon. Bulletin of the Japanese Society of Scientific Fisheries, 49, 765-768.

Shirai, T., Fuke, S., Yamaguchi, K., \& Konosu, S. (1983b). Studies on extractive components of salmonids. II. Comparison of amino acids and related compounds in the muscle extracts of four species of salmon. Comparative and Biochemistry Physiology, 74B, 685-689.

Simopoulos, A. (1997). Nutritional aspects of fish. In J. Luten, T. Börrensen, \& J. Oehlenschläger (Eds.), Seafood from Producer to Consumer, Integrated Approach to Quality (pp. 589-607). London, UK: Elsevier Science.

Skonberg, D., Rasco, B., \& Dong, F. (1993). Effects of feeding high monounsaturated sunflower oil diets on sensory attributes of salmonid fillets. Journal of Aquatic Food Product Technology, 2, 117-133.

Skonberg, D., Rasco, B., \& Dong, F. (1994). Fatty acid composition of salmonid muscle changes in response to a high oleic acid diet. Journal of Nutrition, 124, 16281638

Spinelli, J., \& Mahnken, C. (1978). Carotenoid deposition in pen-reared salmonids fed diets containing oil extracts of red crab (Pleuroncodes planipes). Aquaculture, $13,213-223$. 
Stansby, M. (1967). Fatty acid patterns in marine, freshwater, and anadromus fish. Journal of the American Oil Chemists’ Society, 44, 64-64.

Steiner, P., Broderson, S., \& Liston, J. (1984). Ultrastructural localization of lysosomes in coho salmon and steelhead trout muscle. Journal of Food Science, 49, 975976, 978.

Stone, F. (1970). Enzymatic deamination of adenosine monophosphate (AMP), adenosine and adenine by salmon, crab and scallop muscle extracts. Journal of Food Science, 35, 565-567.

Tinsley, I., Krueger, H., \& Saddler, J. (1973). Fatty acid content of coho salmon, Oncorhynchus kisutch: A statistical approach to changes produced by diet. Journal of the Fisheries Research Board of Canada, 30, 1661-1666.

Tinsley, I., Saddler, J., Krueger, H., \& Lowry, R. (1971). Interactions in the metabolism of polyunsaturated fatty acids in the coho salmon, Oncorhynchus kisutch (Walbaum). International Journal of Biochemistry, 2, 345-348.

Ueda, Y., Hibino, G., Kohmura, M., Kuroda, M., Watanabe, K., \& Sakaguchi, M. (1998). Contents of glutathione in seafoods and its flavor characteristics. Bulletin of the Japanese Society of Scientific Fisheries, 64, 710-714.

Yamaguchi, T., Sato, Y., Ito, M., Moritani, N., \& Hata, M. (1988). The lipid and fatty acid compositions in tissues of cultured and wild coho salmon Oncorhynchus kisutch. Bulletin of the Japanese Society of Scientific Fisheries, 54, 1601-1605.

Yamamoto, M., \& Mackey, J. (1981). An enzymatic method for reducing curd formation in canned salmon. Journal of Food Science, 46, 656-657.

Yamazaki, T., Ito, A., Nozaki, Y., Narita, S., \& Hirota, S. (1983). On astaxanthin content of silver salmon (Oncorhynchus kisutch). Japanese Journal of Nutrition, $41,391-395$. 
Yu, T., \& Sinnhuber, R. (1979). Effect of dietary $\omega 3$ and $\omega 6$ fatty acids on growth and feed conversion efficiency of coho salmon (Oncorhynchus kisutch). Aquaculture, 16, 31-38.

Yu, T., \& Sinnhuber, R. (1981). Use of beef tallow as an energy source in coho salmon (Oncorhynchus kisutch) rations. Canadian Journal of Fisheries and Aquatic Sciences, 38, 367-370.

Yu, T., Landers, M., \& Sinnhuber, R. (1969). Storage life extension of refrozen silver salmon steaks. Food Technology, 23, 1602-1604.

Yu, T., Sinnhuber, R., \& Crawford, D. (1973). Effect of packaging on shelf life of frozen silver salmon steaks. Journal of Food Science, 38, 1197-1199.

Zottola, E., Wagner, M., \& Zoltai, P. (1983). Composition and microbiology of some native Alaskan preserved foods. Journal of Food Protection, 46, 441-443. 


\section{FIGURE LEGENDS}

Figure 1: Free fatty acid (FFA; mg/g muscle) content ${ }^{1}$ in chilled salmon previously treated under different hydrostatic high pressure conditions ${ }^{2}$

${ }^{1}$ Mean values of three $(n=3)$ independent determinations; standard deviations are denoted by bars. Adapted from Ortea et al. (2010).

${ }^{2}$ Treatment abbreviations: C (control), T-1 (135 MPa for $\left.30 \mathrm{~s}\right), \mathrm{T}-2$ (170 MPa for $30 \mathrm{~s}$ ) and T-3 (200 MPa for $30 \mathrm{~s})$.

Figure 2: Fluorescence ratio (FR) assessment ${ }^{1}$ in frozen salmon previously fed with diets including different antioxidant mixtures ${ }^{2}$

${ }^{1}$ Mean values of five $(n=5)$ independent determinations; standard deviations are denoted by bars. Adapted from Ortiz et al. (2009).

2 Diet names: Diet 1 (butylated hydroxytoluene-ethoxyquin mixture), Diet 2 (tocopherol isomers-rich mixture) and Diet 3 (tocopherol isomers-rosemary extract mixture).

Figure 3: Assessment ${ }^{1}$ of trimethylamine-N (TMA-N; $\mathrm{mg} / \mathrm{kg}$ muscle) content, thiobarbituric acid (TBA) value (mg malondialdehyde/ $\mathrm{kg}$ muscle) and browning development (absorbance at $420 \mathrm{~nm}$ ) in raw and cooked salmon that was previously chilled $^{2}$

${ }^{1}$ Mean values of four $(n=4)$ independent determinations; standard deviations are denoted by bars. Adapted from Rodríguez et al. (2008).

2 Sample abbreviations: RS (raw salmon), CS-0 (cooked salmon; 0 days previous chilling), CS-5 (cooked salmon; 5 days previous chilling) and CS-9 (cooked salmon; 9 days previous chilling). 